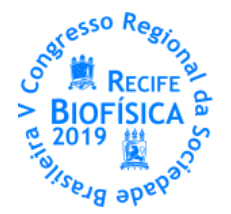

\title{
ALFABETIZAÇÃO CIENTÍFICA NO AMBIENTE ESCOLAR DE ALUNOS DO ENSINO FUNDAMENTAL DA ESCOLA PADRE JOSÉ MATIAS DELGADO
}

\author{
Ryan Cordeiro Silva ${ }^{1 *}$, Camila Aparecida Pereira Monteiro ${ }^{1}$, Jailson José da Silva², Izabel Gomes Souza Sobrinha ${ }^{2}$, \\ Gabriela Marques², Adriana Fontes ${ }^{1}$, Beate Saegesser Santos ${ }^{3}$, Goreti Pereira ${ }^{2}$, Giovannia Araujo de Lima Pereira ${ }^{2}$ \\ ${ }^{1}$ Departamento de Biofísica e Radiobiologia, CCS-UFPE; ${ }^{2}$ Departamento de Química Fundamental, CCEN-UFPE, ${ }^{3}$ Departamento de Ciências \\ Farmacêuticas, CCS-UFPE \\ ${ }^{*}$ ryanc.silva5@gmail.com
}

\section{INTRODUÇÃO}

Em discurso na Universidade de Uppsala na década de 1740, Carls Linnaeus disse que "Deus deu aos homens barbas como ornamentos para distingui-los das mulheres" [1]. Ao falar isso, um aspecto da sociedade em que vivia era simbolizado, o processo de construção do conhecimento da época era subordinado à alegoria da barba do filósofo. Apesar de grandes exemplos de atuação de mulheres na ciência, como Marie Curie, o estereótipo masculino predominou na construção das disciplinas acadêmicas modernas, perdurando um senso comum de que mulheres simplesmente não poderiam ter aptidão para a ciência. Num contexto histórico, a discussão aberta sobre o papel da mulher na prática de ciências ainda é recente, com princípios firmados nos movimentos feministas que surgiram no fim do século XIX. Tal realidade começou a ser problematizada no Brasil apenas da década de 1970, quando começaram as discussões sobre o papel feminino nas ciências. Os avanços conquistados levam ao quadro atual da produção científica brasileira, as mulheres alcançaram um papel mais ativo, participando de quase metade das bolsas de pós-graduação fornecidas por agências de governo que financiam o setor. Mas, ao analisar o número de bolsas de produtividade em pesquisa concedidas a cientistas, os números mostram uma participação feminina de apenas $1 / 3$ do número total de bolsas fornecidas em 2015.

Adicionalmente, os cidadãos vivenciam atualmente a presença de tecnologia em seu cotidiano, facilitando o rápido acesso à informação. Dessa forma, tornar popular o acesso ao conhecimento tornou-se primordial para que os as pessoas possam compreender melhor o mundo e intervir de maneira responsável e crítica no meio em que vivem. $O$ ensino de ciências assume assim um papel muito importante, pois, a longo prazo, orienta-se para a promoção da cidadania e da criação de pensamento crítico. A fluidez da informação nos dias de hoje pode ser assim benéfica quando pensamos nos desafios do primeiro contato da criança com a ciência. Foi pesquisado a respeito da prática de ensino de ciências com professores do Fundamental I, e foi comum a eles apontar dificuldades em promover um ambiente desafiador, propício à investigação e à construção de conhecimento sobre ciências [2]. E, ao pensar nas fases do desenvolvimento infantil, a faixa etária das crianças em séries iniciais é uma etapa extremamente sensível à aprendizagem, contribuindo significativamente na construção da personalidade de cada uma delas. Essa fase é manifestada pelo gosto de imitar, assimilando o mundo exterior para si [3]. Nesse contexto, motivados pela expressão feminina na construção da ciência moderna, vamos descrever aqui atividades lúdicas, baseadas em trabalhos de cientistas brasileiras, que desenvolvemos com crianças de 5 a 7 anos, com fins de colaborar para a construção do conceito de ciência, despertando assim sua curiosidade pelo mundo científico.

\section{MATERIAIS E MÉTODOS}

A alfabetização científica proposta constou de 4 (quatro) encontros/aulas, com frequência semanal, nas turmas do $1^{\circ}$ ano do Ensino Fundamental I. Inicialmente, já no primeiro encontro, foi feito um levantamento em termos de conhecimento e de percepção das crianças no que se refere à ciência e aos cientistas. $\mathrm{E}$, em todas as aulas foram abordados tópicos de pesquisa distintos, porém todos inspirados em cientistas brasileiras e envolvendo a "matéria" como tema de estudo, porém em diferentes escalas de tamanho, que variam desde a escala molecular até dimensões espaciais, dando-lhes noção comparativa de tamanho entre eles e os objetos de estudo científico. A linguagem teórica e prática utilizadas em todos os momentos foram tecnicamente analisadas e adequadas para a faixa etária das crianças. No último encontro foi proposto um desafio a ser solucionado pelas crianças, no intuito de captar o desenvolvimento da alfabetização científica. Para cada encontro, a equipe foi composta por pelo menos dois discentes e dois docentes, além da equipe de produção da mídia audiovisual. Foi ainda objetivo da proposta a produção de uma mídia audiovisual, como forma de registro de todo o processo da alfabetização científica. Essa produção audiovisual (DVD) foi formada pelos seguintes elementos: (i) imagens das atividades elaboradas; (ii) depoimento dos(as) educadores/as, professores/as e pesquisadores/as e participantes do processo e (iii) fala descritiva das atividades, bem como seu passo-a-passo, possibilitando que outras escolas possam entender e repetir as experiências mencionadas. De acordo com a importância da mídia audiovisual como suporte didático, pretende-se que esse produto seja uma ferramenta educacional efetiva, que permita auxiliar e/ou orientar os professores na elaboração de novas metodologias didáticas. Sobre os temas que foram abordados nas aulas, foram selecionadas linhas de estudo de três pesquisadoras. o critério de escolha das mesmas baseou-se no destaque nas respectivas áreas de atuação, para a qual tiveram reconhecimento através de prêmios científicos importantes, como por exemplo, o "L'Oréal-UNESCO For Women in Science", entre outros:

Aula 1 - Inibidores de proteases para o tratamento de doenças negligenciadas: A primeira aula teve como inspiração e representação a pesquisa desenvolvida pela cientista e professora da Universidade Federal de Minas Gerais (UFMG) Rafaela Salgado Ferreira. De seus recentes estudos foi possível destacar dois conceitos principais, o de proteínas, suas formas e funções, e 
então o de proteases, suas aplicações e presença no cotidiano. Foram utilizadas práticas lúdicas de exemplificação, como a alteração da proteína do ovo por agente desnaturante, e inibição da formação de colágeno através da presença de bromelina, uma enzima presente no abacaxi.

Aula 2 - Nanocristais: conceitos e propriedades: Nessa aula, a cientista e professora da Universidade Federal de Pernambuco (UFPE), Beate Santos, ministrou para os alunos alguns dos conceitos que sua pesquisa baseia-se. Através do recurso de um microscópio óptico, foi possível ver a forma e tamanho que cristais de $\mathrm{NaCl}$ adquiriram ao serem moídos por um pilão, e partindo disso o conceito de nanocristais e fluorescência foram introduzidos, com uso de associações também como com os pontos quânticos, que mudam a sua coloração de emissão de luz a medida que mudam de tamanho.

Aula 3 - Descobrindo a composição das estrelas: A astrofísica e professora da Universidade de São Paulo (USP) Beatriz Barbuy, e suas descobertas nas áreas de diagrama cor-magnitude, aglomerados globulares e espectroscopia foi tema chave para a criação dessa terceira aula. De início foi apresentado para as crianças o sistema solar, juntamente com suas dimensões de tamanho e proporcionalidades, exercitados na construção de uma réplica do sistema solar em papel alumínio. Ao contextualizar a pesquisa da Beatriz Barbuy, foi feita uma atividade lúdica em que consistia adivinhar a temperatura e distância das estrelas ilustradas por lâmpadas de diferentes cores e intensidade de brilho.

Aula 4 - Proposta de problema e considerações finais: Nesse encontro foi proposto um diálogo coletivo com o objetivo de resolver o problema que consistia em "como obter de volta o sal diluído em água?". No final da aula foi feito um questionário com perguntas de múltipla escolha a respeito dos temas abordados em sala de aula e ciência.

\section{RESULTADOS E DISCUSSÃO}

Na primeira abordagem com os alunos, fizemos um questionamento de modo a identificar a forma representativa e assimilativa com enxergavam a ciência. Optamos por mostrar quatro fotos de pessoas escolhidas aleatoriamente, duas mulheres e dois homens, dentre elas fotos de duas cientistas mulheres. Foi perguntado às crianças se as pessoas das fotos se assemelhariam com um cientista, e através das respostas, identificamos um perfil de cientista associado a livros e vestimentas de laboratório, itens visuais presentes nas fotos que mais obtiveram afirmação delas, como também ainda persiste o estereótipo da pessoa de idade avançada e com barba. Tal associação de características também foram observadas em estudos com a mesma metodologia em grupos de diferentes faixas etárias [4]. Ao longo das aulas, foi pedido às crianças uma representação em forma de desenho sobre o conteúdo passado na sala de aula, tendo como perguntas mediadoras as seguintes: (i) onde você vê a prática de ciências? (ii) quais itens do seu dia a dia se assemelham ao dado em sala de aula? e (iii) o que mais se destacou para você no experimento realizado? Os desenhos tiveram em sua maioria um perfil categórico ao que se trata sobre ciências, com ilustrações de ambientes como o laboratório ou ainda itens que são geralmente usados nesse ambiente, como óculos de proteção (Figura 1). Tais tipos de expressão podem revelar um pensamento que remete à ciência reservada a interiores de laboratórios e de prática sistemática e restrita, com uso de equipamentos e itens laboriosos. Para Weingart, Muhl e Pansegrau, o laboratório é tido como um lugar "secreto" ou "perigoso" nos filmes analisados em seu estudo, remetendo a um perfil de isolamento do cientista do resto da sociedade[5]. Em contraponto, é importante fazer uma desconstrução dessas representações antigas e planejar o conteúdo transmitido aos alunos numa perspectiva científica e pedagógica integrada, que os permitam estabelecer contato com um ambiente de exploração de diversas manifestações de fenômenos naturais, com fins de testar e questionar hipóteses, expor suas ideias e confrontá-las com a de outros estudantes, favorecendo a aquisição de conhecimentos necessários à alfabetização científica e exercício da cidadania.

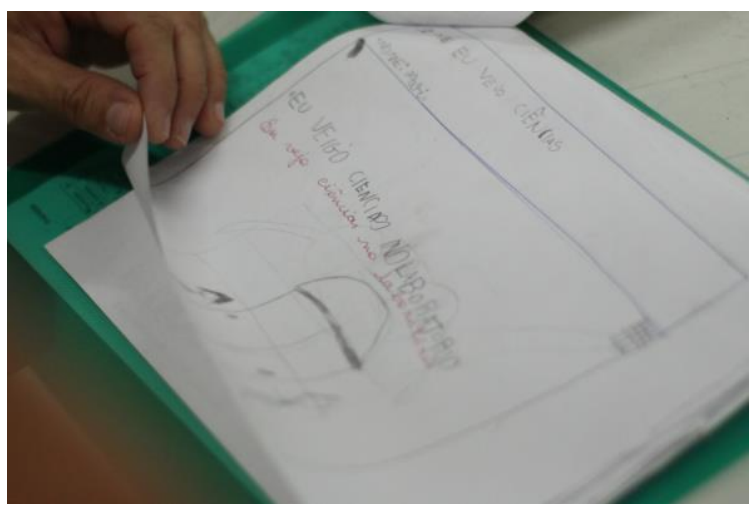

Figura 1. Desenho de um laboratório com a frase "Eu vejo ciências no laboratório", realizado por um aluno do Fundamental I. Foto: Gabi Saegesser

Após a realização das aulas programáticas, no $4^{\circ}$ encontro com os alunos, foi proposto um desafio, a professora ministrante da aula fez a seguinte pergunta: "Após dissolver o sal de cozinha com a água, existe maneira de obtê-lo de volta?". Com auxílio de ilustrações através de slides, foi explicado o processo de solvatação da água com o sal de cozinha, em nível molecular. No decorrer do desafio, observou-se um avanço no posicionamento dos alunos para com o conteúdo. Uma postura inicialmente pouco clara e retraída foi dando espaço para construção de posicionamentos e respostas coerentes, como a afirmação de uma das alunas: "As moléculas de água e sal estão juntinhas por alguma força que não deixam elas soltarem". É notado a inserção de um possível associação prévia com forças intermoleculares, remetendo a conceitos ministrados na aula 2 sobre nanocristais. É visto também a construção do saber auxiliado pelo uso de signos no psicológico da criança, quando ela começa a usar os termos "moléculas" e "forças". Os signos, segundo Vigostky (2007), são instrumentos psicológicos que auxiliam o sujeito nas ações da psique, conduzindo a novas formas de processos psicológicos enraizados na cultura[6]. A Figura 2, obtida em atividade com a professora regular da escola, revela uma associação do aluno em relação a alguns signos expostos na aula 3. A forma de abordagem da aula foi capaz de possibilitar atividades psicológicas intencionais, deliberadas e por meio disso a criança vai incorporando as experiências e significações construídas [7].

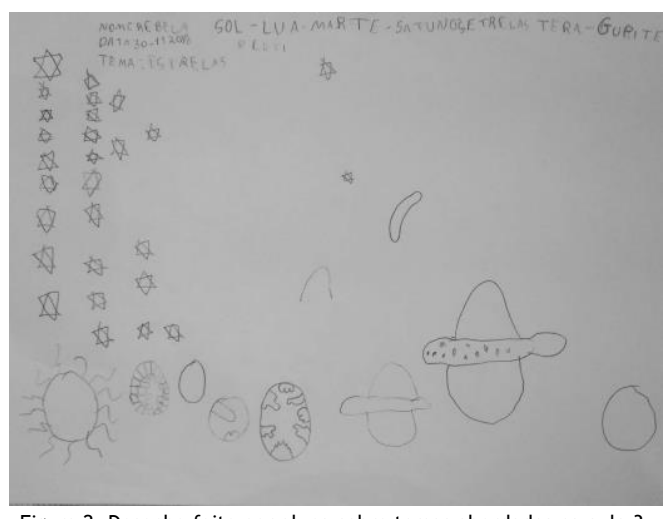

Figura 2. Desenho feito por aluna sobre temas abordados na aula 3. 
$\mathrm{Na}$ aula 4 foi realizado o questionário e uma das perguntas consistia em "Quais ambientes você acha possivel praticar ciências?". Alternativas como floresta, laboratório, e sala de aula foram bastante escolhidas entre as crianças, sob argumento de que existe diferentes estudos sobre animais, plantas e pessoas. A justificativa dada se contrapõe às ideias iniciais sobre ciência obtidas no primeiro encontro, demonstrando uma identificação de diferentes formas de produzir ciência, como também uma aproximação da construção do conhecimento com o ambiente escolar. Por fim, foi produzido um material audiovisual com todos os conceitos e práticas dadas em sala de aula. Esse material foi transformado em DVD com o intuito de transmitir a experiência para outros docentes. A prática e o ensino de ciências para crianças das primeiras séries do Ensino Fundamental I ainda é um desafio quando analisamos a formação polivalente dos docentes, que preconizam a aprendizagem da leitura e escrita das crianças, priorizando o ensino das áreas de português e matemática em detrimento do ensino de ciências. Ducatti-Silva analisou a formação dos professores de séries iniciais em cinco cursos de pedagogia de instituições do Estado de São Paulo. Nesse trabalho, quando os licenciandos foram questionados sobre as maiores dificuldades em ministrar aulas de ciências, a falta de domínio do conteúdo e a sua contextualização foram as respostas mais frequentes[8]. Frente a isso, o material apresenta formas acessíveis de ensinar ciências, retiradas do dia a dia do aluno, como ovos, álcool, lâmpadas, pulseiras fosforescentes entre outros. Cabe aos professores dos anos iniciais o papel de associar conceitos cotidianos e mediar o processo que vai abrindo caminho para a construção do conceito de ciência.

\section{CONCLUSÕES}

Esse projeto inspirou-se em cientistas brasileiras para trabalhar o conceito de ciência com crianças do Ensino Fundamental I. Os principais resultados indicaram que a sequência didática apresentada nas aulas auxiliou no avanço progressivo dos alunos, evidenciado nas discussões coletivas realizadas dentro da sala de aula. A forma como as mulheres foram representadas nas aulas inicia aos alunos um contato com um mundo científico diferente do habitual, com a quebra do estereótipo de cientista na figura masculina, vestido de jaleco e com barba. A desconstrução do ambiente laboratorial para a realização de experimentos também foi encontrada quando as crianças participaram ativamente das práticas pedagógicas realizadas dentro da sala de aula, podendo as mesmas associar o exercício de ciências com o seu cotidiano. A realização de atividades de caráter investigativo apareceu como possibilidade para a construção de conceituais e procedimentais. Ao final, espera-se que o material audiovisual criado no projeto auxilie aos docentes que desejam trabalhar o ensino de ciências com as crianças, ressaltando aqui também a importância do mesmo para a boa progressão da psique infantil. A quebra da barreira entre, a pesquisa de excelência realizada nas universidades brasileiras e o Ensino Fundamental I, foi um destaque do projeto, ajudando o despertar pela ciência sob uma ótica da pedagogia.

\section{REFERÊNCIAS}

BLUNT, W. The Compleat Naturalist: A Life of Linnaeus. Frances Lincoln Publishers. v.3, p. 157, 2002.

ROSA, C. W.; PEREZ, C. A. S.; DRUM, C. Ensino de física nas séries iniciais: concepções da prática docente. Investigações em Ensino de Ciências, v. 12, n. 3, p.357-368, 2007.

WALLON, H. As Etapas Da Socialização Da Criança. Lisboa, 1953.

SOARES, G.; SCALFI, G. Adolescentes e o imaginário sobre cientistas: análise do teste "Desenhe um cientista" (DAST) aplicado com alunos do $2^{\circ}$ ano do Ensino Médio. In: CONGRESO
IBEROAMERICANO DE CIENCIA, TECNOLOGÍA, INNOVACIÓN Y EDUCACIÓN. Buenos Aires (Argentina), 12-14 nov. 2014.

WEINGART, P.; MUHL, C.; PANSEGRAU, P. Of power maniacs and unethical geniuses: science and scientists in fiction film, 12, 279287, 2003.

VIGOTSKY, L. S. A formação social da mente. Martins Fontes. v.7, 2007.

LIMA, M. E. C. de C.; MAUÉS, E. Uma releitura do papel da professora das séries iniciais no desenvolvimento e aprendizagem de ciências das crianças. Ensaio - Pesquisa em Educação em Ciências. v.8, n.2, 2006.

DUCATTI-SILVA, K.C. A formação no curso de Pedagogia para o ensino de ciências nas séries iniciais. Dissertação de Mestrado, Programa de Pós-Graduação em Educação, Faculdade de Filosofia e Ciências, Universidade Estadual Paulista "Júlio de Mesquita Filho", Marília, SP, 2005. 